\title{
Emergence of choice strategies in the rat: Shift-stay differentiation precedes win-lose differentiation
}

\author{
ALAN G. GITTIS, HOLLY STARK, and CHERYL ARNOLD \\ Westminster College, New Wilmington, Pennsylvania \\ and \\ BETH GETER, DARRELL FRAZIER, and DAVID S. OLTON \\ The Johns Hopkins University, Baltimore, Maryland
}

\begin{abstract}
The choice strategies of rat pups between 12 and 21 days of age were studied in a two-choice discrimination procedure that used access to a nonlactating anesthetized dam as a reward. After receiving a reward (win) or not receiving a reward (lose), a pup repeated a previous choice (stay) or made an alternative response (shift). At 12 and 15 days of age, pups demonstrated neither a stay nor a shift response strategy; at 18 and 21 days of age, pups had a robust tendency to shift. Winning or losing did not alter behavior until 21 days of age, at which point winning produced a greater tendency to return to the initially visited location for rats in the stay condition.
\end{abstract}

At the time of weaning, under naturalistic conditions, an animal generally undergoes a transition from being cared for in a relatively restricted environment to living independently in a much more extended environment. In the laboratory rat, during the 3rd week of life, physiological, morphological, and behavioral changes permitting adaptation to the postweaning environment occur rapidly. These changes, which include the opening of the eyelids at 15 days and adult-like locomotory pattern (see Bolles \& Woods, 1964), are accompanied by changes in the ability to metabolize solid food (Babicky, Ostadalova, Parizek, Kolar, \& Bibr, 1970) and development of the central nervous system, including rapid neurogenesis in the hippocampus (Altman \& Das, 1965), a structure thought vital in the mapping and memory of the distal environment (O'Keefe \& Nadel, 1978).

To negotiate an extended environment, in which resources are often "patchy," animals employ strategies that include the memory for places visited (Olton, Handelman, \& Walker, 1981). The purpose of our experiment was to study the development of these strategies. For this, we used a Y-maze discrimination procedure, with the animals being tested in a variant of an apparatus used by Kenny and Blass (1977) in which pups as young as 7 days of age have demonstrated the ability to acquire, reverse, and retain a simple spatial discrimination. To solve the discriminations used in the present study, the

This research was conducted during sabbatical leave granted to the first author from Westminster College, which also generously supported the manuscript preparation. Funding for the experiment was provided by NIMH Research Grant MH 24213, awarded to D. Olton. Reprint requests should be sent to A.G. Gittis, Psychology Department, Westminster College, New Wilmington, PA 16172. pups had to adopt a win-stay, a win-shift, a lose-stay, or a lose-shift strategy. The pups were tested just before and during the 3rd week of life.

\section{METHOD}

\section{Experimental Design}

The experiment used a 4 (days of age) $\times 2$ (stay or shift) $\times 2$ (win or lose) design. Pups were tested at $12,15,18$, or 21 days (D) of age. For the forced run, pups were either allowed to attach to a nipple of an anesthetized dam (win) or prevented from doing so (lose). For the choice run, the correct arm (which allowed the pup to attach to a nipple) was either the same arm entered during the forced run of that trial (stay) or the opposite arm (shift). The experiment was continued until 10 pups were in each of the groups for a total of 160 pups.

\section{Subjects}

The rat pups came from litters born to Sprague-Dawley mothers in the laboratory at Johns Hopkins University. Two days after birth, each litter was reduced to 10 pups and housed with the mother until testing began.

\begin{abstract}
Apparatus
A Y-maze, similar to that described by Stoloff and Blass (1983), was constructed of plywood. The walls were $9 \mathrm{~cm}$ high. A $9 \times 8 \mathrm{~cm}$ startbox was attached to two arms, each $5 \mathrm{~cm}$ wide and $19 \mathrm{~cm}$ long. A Plexiglas door, the start door, separated the startbox from the arms. Each arm led to a $12 \times 21 \mathrm{~cm}$ goal area. Plexiglas doors, the goal doors, separated the arms from the goal area. Each goal door had holes in it to permit the passage of odors between the goal area and the alleys. The goal area was designed to accommodate an anesthetized reclining dam, positioned so that her anterior nipples could be reached from one arm, while the posterior nipples could be reached from the other arm. Gaps around the dam's body were filled with clay to prevent the rat pups from reaching any part of her other than her ventrum. The entire apparatus was housed in a box with a Plexiglas lid. The temperature in the box was regu-
\end{abstract}


lated by a Variac connected to heating tapes below the floor of the box.

\section{Procedure}

Deprivation and adaptation. Groups of 4 to 6 pups were placed in the Y-maze 14 to $16 \mathrm{~h}$ prior to testing. The pups were all of the same age, but came from several litters. The temperature was maintained at $30^{\circ}-33^{\circ} \mathrm{C}$ for the $12-\mathrm{D}$ pups and $24^{\circ}-27^{\circ} \mathrm{C}$ for all other pups. Just prior to testing, the pups were placed in a $28 \times 22 \mathrm{~cm}$ plastic tub within the temperature-controlled box. An anesthetized dam, not the mother of any of the pups, was positioned in the goal area as described above. Each pup was then placed in each goal compartment and allowed to attach to a nipple for $15 \mathrm{sec}$.

Testing. Each pup was randomly assigned to one of the four discrimination procedures: win-shift, win-stay, lose-shift, lose-stay. Each test trial was composed of a forced run and a choice run. For the forced run, one alley was blocked by a piece of wood so that the pup could not enter it. The pup was placed in the startbox and left there for a few seconds. The start door was raised. The pup entered the open alley and went to the end of it. For the two win procedures, the goal door was raised and the pup was permitted to attach to a nipple for $15 \mathrm{sec}$. For the two lose procedures, the goal door remained in place, blocking access to the dam.

The pup was returned to the startbox for the choice run of the trial. The wooden barrier blocking the alley during the forced run was removed so that both alleys were available. The pup entered one alley and went to the end of it. If the pup entered the correct alley, the goal door was raised and the pup was allowed to attach to a nipple for $15 \mathrm{sec}$. If the pup entered the incorrect alley, the goal door remained closed and the pup was removed after contacting the goal door. For the two shift procedures, the alley that was blocked for the forced run was correct. For the two stay procedures, the alley that was open (and entered) for the forced run was correct.

The pups in a group were tested successively. The intertrial interval was approximately $4 \mathrm{~min}$. Each pup was tested for 30 trials, or until a criterion of 9 correct responses in 10 consecutive trials was reached. If a pup failed to approach the goal area in $2 \mathrm{~min}$ on either the forced run or the choice run for 2 consecutive trials, testing was terminated. Data from pups that failed to respond for 2 trials were not considered in the data analysis.

The arm that was blocked for the forced run was alternated for each trial, with the constraint of a between-trials correction procedure. If the pup chose the incorrect arm on the choice run of a trial, the arm that was blocked for the forced run of the next trial remained the same as on the previous forced run.

Data analysis and statistics. Choice accuracy was evaluated by three different response measures. The baseline predisposition to shift or stay was assessed by the total number of correct responses in the first $\mathbf{1 0}$ trials. The ability of the rats to discriminate the response-reinforcement contingency throughout the session was assessed by two measures. The first was the percentage of total responses that were correct throughout the session. The second was the highest criterion level achieved during the 30 trials, which was the greatest number of correct responses in each consecutive block of 10 trials beginning with Trials $1-10$, then $2-11,3-12$, and so forth.

The statistical significance of the effects was evaluated with the analysis of variance (ANOVA) test supplemented by the Scheffé test.

\section{RESULTS}

Of the 180 rats that began testing, 20 failed to reach the criterion for inclusion in the results $(9$ correct responses in 10 consecutive trials, or a total of 30 trials). The 12-D pups were more likely to fail than the older ones, but these failures were equally distributed across all four groups. All the remaining pups performed consistently, completing each run from the startbox to the goal generally in less than $30 \mathrm{sec}$.

Figure 1 summarizes the performance of subjects in the four strategy conditions (win-shift, lose-shift, win-stay, lose-stay) in terms of percent correct responses. The pattern of performance during the first 10 trials and also in terms of highest criterion level reached was essentially identical. This means that the basic pattern of responding for each animal was established in the first 10 trials, changing little as testing progressed. Consequently, only the ANOVAs calculated on the percent correct measure will be reported.

The shift-stay dimension failed to influence the choice accuracy of the 12-D and 15-D pups, but markedly affected the choice accuracy of the 18-D and 21-D pups [age $\times$ shift-stay interaction, $F(3,14)=23.8, p<.001]$. Both groups of younger pups (12-D and 15-D) began testing with no obvious bias to shift or stay, and showed little sign of an ability to acquire the discrimination. Their choice accuracy during the forced trial hovered around $50 \%$ correct. Both groups of older pups (18-D and 21D) began testing with a strong bias to shift, which continued throughout testing and resulted in much greater accuracy in the shift groups than in the stay groups (Figure 1). The very low choice accuracy of the 18-D and 21-D subjects in the stay conditions indicates a strong disposition to shift despite the presence of the stay contingency.

The forced-run outcome (win or lose) had a significant effect on the choice accuracy of 21-D pups in the stay group (compare Figures $1 c$ and 1d) but not in the shift group, and had no significant effect on the choice accuracy of 18-D pups in either group, as shown by a significant three-way interaction $[F(3,144)=4.7, p<.005]$. The 21-D lose-stay pups had lower choice accuracy than that of any other group [Scheffé contrast, $s(3 / 144)=.193$, $p=.05] ; 2$ pups in this group failed to make a correct response in the 30 trials.

Although the older pups in the shift condition were much more likely to reach the 9 correct out of 10 acquisition criterion, there were several instances in which younger pups reached criterion under either the shift or the stay contingency and a few instances in which older pups reached the criterion under win-stay. To determine the likelihood that criterion could be reached by chance factors alone, the proportion of pups that could be expected to reach criterion during 30 test trials by chance was estimated with the binomial theorem. This estimate was then compared with the actual proportion of pups in each group that reached the acquisition criterion using the test for significance between two proportions (Bruning \& Kintz, 1977). It was determined that, to rule out chance factors, at least 4 of the 10 pups in each group would have to reach the acquisition criterion. Under these constraints, only the 18-D and 21-D subjects in the shift conditions reliably achieved the acquisition criterion, with one 


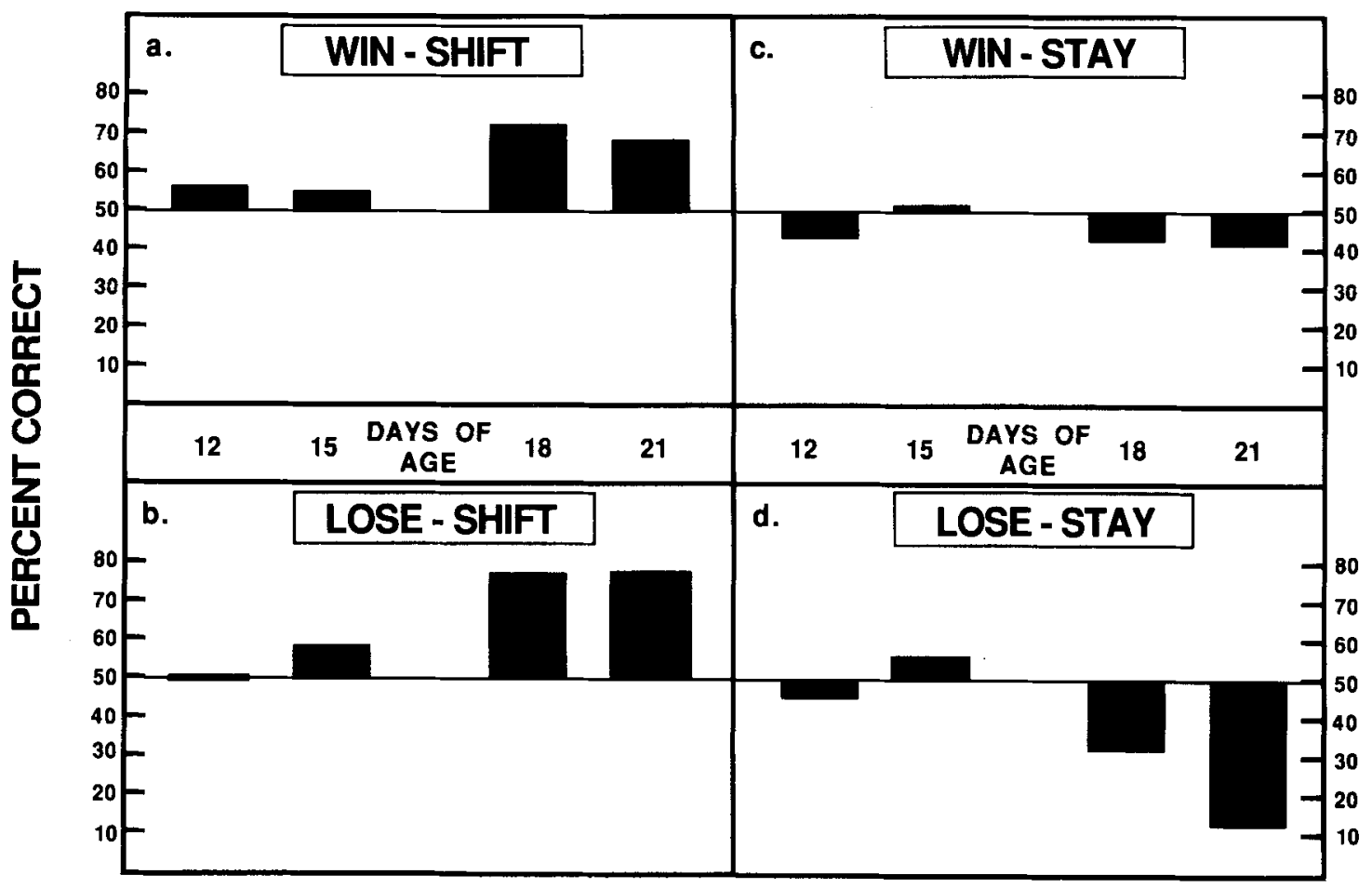

Figure 1. Percent correct responses on choice run of rat pups at four different ages. (a) Win-shift, (b) lose-shift, (c) winstay, and (d) lose-stay.

exception-the 15-D lose-shift subjects in which 4 out of 10 subjects did achieve criterion level performance. In the older shift groups, 6 to 8 pups reached criterion.

\section{DISCUSSION}

Between 12 and 21 days of age, rat pups changed their choice strategies in the Y-maze discrimination task. Pups that were 15 days of age or younger were not affected by either the outcome of the forced run (win or lose) or the response-reinforcement contingencies of the choice run (stay or shift), and their choice accuracy during the 30 test trials remained near the level expected by chance. In contrast, the older pups had a strong predisposition to shift rather than stay, a weak predisposition to return to an initially visited place if reinforcement was found there (win-stay), and a marked divergence of choice accuracy in the various experimental procedures, ranging from almost perfect to very poor. The transition periods for these effects were different. The influence of the shiftstay dimension appeared at 18 days, while the influence of the win-lose dimension did not appear until 21 days of age.

Alternation performance changes during development have been noted, but the time course of these changes has varied. In this study, alternation appeared during the beginning of the 3rd week of life, similar to the findings of Smith and Spear (1978) but different from those of older studies (Egger, Livesey, \& Dawson, 1973; Kirkby, 1967), which reported the appearance of alternation dur- ing the 4th week of life. In the Smith and Spear (1978) study and in the present one, the pups were familiar with the stimuli in the apparatus prior to testing, a factor that appears to accelerate the appearance of alternation.

The transition in performance between 15 and 18 days of age was abrupt. At 15 days of age, pups engaged in a random pattern of choice that was virtually indiscriminable from that of the 12-day-old pups. At 18 days of age, pups had high levels of choice accuracy, similar to those of adult rats. Gaffan and Davies (1981) argued that performance on shifting or staying tasks may be divided into two components, spontaneous alternation and associative memory. The developmental patterns observed here certainly fractionate in this way. The truly "spontaneous" nature of alternating in the 18-day-old pups was obvious in the first few trials of the task. The subsequent difference between the 21-day-old pups in the win-stay and losestay conditions involves the modification of choice after nonreward.

The mediating events underlying the emerging behaviors observed in this study were not determined. There are several classes of events possible. The incentive characteristics of the dam would be different to 15- and 18-day-old pups, since the value of the dam becomes more dependent on milk availability (Blass, Hall, \& Teicher, 1979). Because the dams used in this study were nonlactating, shifting would be an appropriate response for the older pups in all the conditions. However, the incentive factor alone fails to account for why younger pups showed no evidence of adopting any response strategy, since they 
should be highly motivated to return to an alley in which they had an opportunity to suckle.

Several other events may also have played a role. A 15-day-old pup often has its eyes only partially open, and an 18-day-old pup has had at least 3 more days of visual experience. Rudy, Stadler-Morris, and Albert (1987) found that between 16 and 21 days of age, a rat becomes progressively more skilled in solving spatial problems involving visual cues. Performance on the spatial problems used by Rudy et al. (1987) and alternation tasks has been closely linked to hippocampal circuitry. Thus, the rapid neurogenesis of the hippocampus that occurs in the 3rd week of life (Altman \& Das, 1965) is also likely to be relevant.

This study has shown that as a rat pup approaches weaning, behaviors appear which would be of benefit in dealing with the environment beyond the home nest. At 18 days of age, a strong shifting strategy appears in a twochoice discrimination task, implying the emergence of a memory for a place visited. At 21 days of age, behaviors appear which indicate that what is found there affects choice.

\section{REFERENCES}

Altman, J., \& Das, G. P. (1965). Autoradiographic and histological evidence of postnatal hippocampal neurogenesis in rats. Journal of Comparative Neurology, 124, 319-336.

Babicky, A., Ostadalova, I., Parizek, J., Kolar, J., \& Bibr, B. (1970). Use of radioisotope techniques for determining the weaning period in experimental animals. Physiologia Bohemoslovaca, 9, $457-467$.
Blass, E. M., Hall, E. G., \& TEIChER, M. H. (1979). The ontogeny of suckling and ingestive behaviors. In J. M. Sprague \& A. N. Epstein (Eds.), Progress in psychobiology and physiological psychology (Vol. 8, pp. 243-299). New York: Academic Press.

BolLEs, R. C., \& Woods, P. J. (1964). The ontogeny of behaviour in the albino rat. Animal Behaviour, 12, 427-441.

Bruning, J. L., \& KINTZ, B. L. (1977). Computational handbook of statistics (2nd ed.). Glenview, IL: Scott, Foresman.

Egger, G. J., Livesay, P. J., \& Dawson, R. G. (1973). Ontogenetic aspects of central cholinergic involvement in spontaneous alternation behavior. Developmental Psychobiology, 6, 282-299.

GafFan, E. A., \& Davies, J. (1981). The role of exploration in winshift and win-stay performance on a radial maze. Learning \& Motivation, 12, 289-299.

KenNy, J. T., \& Blass, E. M. (1977). Suckling as incentive to instrumental learning in preweanling rats. Science, 196, 898-899.

KIRKBY, R. J. (1967). A maturational factor in spontaneous alternation. Nature, $215,784$.

O'KEEFE, J., \& NADEL, L. (1978). The hippocampus as a cognitive map. Fairlawn, NJ: Oxford University Press.

Olton, D. S., Handelman, G. A., \& Walker, J. A. (1981). Spatial memory and food searching strategies. In A. C. Kamil \& T. D. Sargent (Eds.), Foraging behavior: Ecological, Ethological and psychological approaches (pp. 333-354). New York: Garland STPM Press.

Rudy, J. W., Stadler-Morris, S., \& Albert, P. (1987). Ontogeny of spatial navigation behaviors in the rat: Dissociation of "proximal" and "distal"-cue-based behaviors. Behavioral Neuroscience, 101, $62-73$.

SMITH, G. J., \& SPEAR, N. E. (1978). Effects of the home environment on withholding behaviors and conditioning in infant and neonatal rats. Science, 202, 327-329.

Stoloff, M. L., \& BLASs, E. M. (1983). Changes in appetitive behavior in weanling-age rats: Transition from suckling to feeding behaviors. Developmental Psychobiology, 16, 439-453.

(Manuscript received April 15, 1987; revision accepted for publication September 22, 1987.) 